\title{
Tail vibration - a newly described defensive behaviour of the Aesculapian snake Zamenis longissimus
}

\author{
ANGEL DYUGMEDZHIEV* \\ Institute of Biodiversity and Ecosystem Research, Bulgarian Academy of Sciences, 2 Gagarin Street, 1113 Sofia, Bulgaria \\ *Author e-mail: angel_diugmedjiev@abv.bg
}

$T_{\text {in }}^{\text {hed }}$ he defensive behaviour of numerous snake species may include tail raising or tail vibration. Defensive tail displays generally function as a warning signal, a decoy, or both. The role of the tail display as a warning or intimidating signal is usually associated with the presence of bright colours of the tail, which serve to warn the predator of a potentially venomous bite, or a noxious discharge of the cloacal scent glands (Bogert, 1968; Greene, 1973; Parker \& Grandison, 1977; Gibbons \& Dorcas, 2002; Araújo \& Martins, 2006). The decoy role of the tail display is observed in numerous venomous and non-venomous species, which use tail vibration to divert the predator's attack from the head, leaving it time to escape or attack the predator (Greene, 1973; Johnson, 1975; Jackson, 1979; Arnold \& Bennett, 1984; Kochva \& Golani, 1993; McCallum, 2006). Additionally, the tail display may serve as a flash display, which disorients the predator, allowing the snake to escape (Robinson, 1969; Greene, 1973).

The Aesculapian snake, Zamenis longissimus (Laurenti, 1768), is distributed from the north-east of the Iberian Peninsula and southern Europe, through Central Europe to the Carpathians and some isolated locations east of them, and south to the central part of the Apennines and southern parts of the Balkan Peninsula, the northern parts of Asia Minor and the Caucasus region (Speybroeck et al., 2016). In Bulgaria, the species is found throughout the country, most commonly in areas up to $1500-1600 \mathrm{~m}$ a.s.l. (Stojanov et al., 2011). In the present study the author describes a novel defence behaviour for the species.

An adult specimen of $Z$. longissimus was captured on 29 August 2015 near Karlukovo Village in north-western Bulgaria ( $43^{\circ} 10^{\prime} 46^{\prime \prime} \mathrm{N}, 24^{\circ} 3^{\prime} 32^{\prime} \mathrm{E}$ ) during an ecological study of snakes in the country. The specimen was measured (SVL = $77 \mathrm{~cm}, \mathrm{TL}=17.9 \mathrm{~cm})$, weighed ( $\mathrm{W}=41.04 \mathrm{~g})$, photographed (Fig. 1) and then released at the site of capture. Immediately after capture, the snake made several attempt to bite. During the photo session, while the snake was restrained by the author, it started a rapid lateral vibration of the tip of its tail. This behaviour was exhibited while the head and the anterior part of the body were gently covered with the palms of the author's hands in order to try to keep the snake still. During the vibration, the snake's tail was placed on the ground. While vibrating its tail, the snake's body was partially coiled with the head positioned in one end and the tail at the other. Vibration of the tail ceased a few seconds after the head and the anterior part of the body were uncovered by the author's

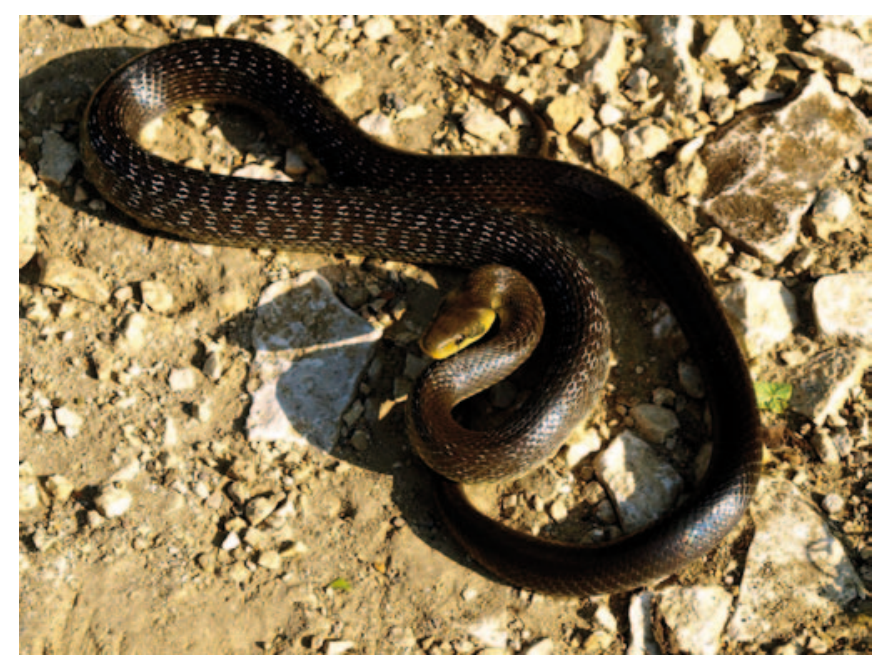

Figure 1. The individual Zamensis longissimus in which defensive tail vibration was observed

palms. The behaviour was exhibited again on both a second and the third attempt to cover the anterior part of the snake's body.

Similar defensive tail vibration is well documented in numerous snake species (Greene, 1973; Johnson, 1975; Jackson, 1979; Arnold \& Bennett, 1984; Kochva \& Golani, 1993; Mullin, 1999; McCallum, 2006). Predators have been shown to respond to tail behaviours by attacking the tail instead of the head (Jackson, 1979). Defensive tail vibration is well documented for another representative of the Zamenis genus - Zamenis situla (Linnaeus, 1758) (see Speybroeck et al., 2016) as well as for species of the closely related genus Elaphe (e.g. Elaphe schrenckii Strauch, 1873, Elaphe quatuorlineata Lacepede, 1789, Elaphe suromates (Pallas, 1811) and Elaphe dione (Pallas, 1773) (Bannikov et al., 1977; Speybroeck et al., 2016)). However, at least to the author's knowledge, this behaviour has never been documented for Z. longissimus. The usual defence behaviours of this species include trying to escape, hissing, biting and expulsion of the content of the cloacal scent glands (the author's personal observations; Rubio \& Gosá, 2010; Stojanov et al., 2011; Speybroeck et al., 2016). It seems that tail vibration may be used as a last resort by $Z$. longissimus, when the snake is unable to escape. This behaviour likely diverts the attention of the 'attacker' from the vulnerable head area of the snake, using the tail as a decoy. This statement could be supported 
by the fact that this behaviour was observed after each of the several attempts of approaching and covering the snake's head with the author's palm. By diverting the attacker's attention to the tail area, the snake could have more time to escape, cover its head or attack the predator (Greene, 1973; Johnson, 1975; Jackson, 1979; Arnold \& Bennett, 1984; Kochva \& Golani, 1993; McCallum, 2006). Additionally, by attacking the tail, the predator could be exposed to the noxious scent of the cloacal scent glands (Greene, 1973). However, this behaviour seems to be very rare for this species as it was observed in only one individual of a total of 45 captured and measured individuals (frequency of occurrence $=2.22 \%$ ). In contrast, this behaviour seems to be very common for $Z$. situla: frequency of occurrence $=$ $50 \%$; total individuals captured and measured $=8$ (the author's personal observations).

\section{ACKNOWLEDGEMENTS}

This work was partially supported by the Bulgarian Ministry of Education and Science under the National Research Program "Young scientists and postdoctoral students" approved by DCM № 577 / 17.08.2018. All fieldwork was carried in accordance to Ministry of Environment and Water of Bulgaria Permit № 520/23.04.2013 and № 656/08.12.2015. The author thanks an anonymous reviewer for helping to improve the manuscript.

\section{REFERENCES}

Araújo, M.S. \& Martins, M. (2006). Defensive behaviour in pit vipers of the genus Bothrops (Serpentes, Viperidae). Herpetological Journal 16: 297-303.

Arnold, S.J. \& Bennett, A.F. (1984). Behavioural variation in natural populations. III: Antipredator displays in the garter snake Thamnophis radix. Animal Behaviour 32: 1108-1118.

Bannikov, A.G. Ishtenko, V.G. Rustamov, E.K. \& Sterbak, N.N. (1977). Amphibian and reptile fauna of the USSR. Moscow, Education, 415 pp. (in Russian)

Bogert, C.M. (1968). A new genus and species of dwarf boa from southern Mexico. American Museum Novitates 2354: 1-38.
Gibbons, J.W. \& Dorcas, M.E. (2002). Defensive behavior of cottonmouths (Agkistrodon piscivorus) toward humans. Copeia 2002: 195-198.

Greene, H.W. (1973). Defensive tail display by snakes and amphisbaenians. Journal of Herpetology 7: 143-161.

Jackson, J.F. (1979). Effects of some ophidian tail displays on the predatory behavior of grison (Galictis sp.). Copeia 1979: 169-172.

Johnson, C.R. (1975). Defensive display behaviour in some Australian and Papuan-New Guinean pygopodid lizards, boid, colubrid and elapid snakes. Zoological Journal of the Linnean Society 56: 265-282.

Kochva, E. \& Golani, I. (1993). Tail display in Atractaspis engaddensis (Atractaspididae, Serpentes). Copeia 1993: 226-228.

McCallum, M.L. (2006). Tail-coiling in ringneck snakes: flash display or decoy? Herpetological Natural History 10: 9194.

Mullin, S.J. (1999). Caudal distraction by rat snakes (Colubridae, Elaphe): a novel behaviour used when capturing mammalian prey. The Great Basin Naturalist 59: 361-367.

Parker, H.W. \& Grandison, A.G.C. (1977). Snakes: a Natural History. 2nd Edition, St Lucia, University of Queensland Press, $108 \mathrm{pp}$.

Robinson, M.H. (1969). Defences against visually hunting predators. In Evolutionary Biology, Vol. 3, 225-259 pp., Dobzhansky, T. Hecht, M.K. \& Steere, W.C. (Eds.). New York, Appleton-Century-Crofts.

Rubio, X. \& Gosá, A. (2010). Culebra de Esculapio - Zamenis longissimus. In Enciclopedia Virtual de los Vertebrados Españoles, 1-21 pp. Salvador, A. \& Marco, A. (Eds.). Madrid, Museo Nacional de Ciencias Naturales.

Speybroeck, J. Beukema, W. Bok, B. \& Voort, J.V.D. (2016). Field guide to the Amphibians and Reptiles of Britain and Europe. London, Bloomsbury Publishing Plc, 432 pp.

Stojanov, A. Tzankov, N. \& Naumov, B. (2011). Die Amphibien und Reptilien Bulgariens. Frankfurt am Main, Chimaira, $588 \mathrm{pp}$.

Accepted: 25 July 2020 